\title{
The astrobiological mission EXPOSE-R on board of the International Space Station
}

\author{
Elke Rabbow', Petra Rettberg', Simon Barczyk', Maria Bohmeier', Andre Parpart ', \\ Corinna Panitz', Gerda Horneck', Jürgen Burfeindt', Ferdinand Molter ${ }^{3}$, \\ Esther Jaramillo ${ }^{4}$, Carlos Pereira ${ }^{4}$, Peter Weiß ${ }^{5}$, Rainer Willnecker ${ }^{5}$, René Demets ${ }^{6}$, \\ Jan Dettmann ${ }^{6}$ and Guenther Reitz' \\ ${ }^{1}$ Radiation Biology, Institute of Aerospace Medicine, DLR, D-51147 Cologne, Germany \\ e-mail: elke.rabbow@dlr.de \\ ${ }^{2}$ Institute of Aerospace Medicine, RWTH Aachen, D-52057 Aachen, Germany \\ ${ }^{3}$ Kayser-Threde GmbH, D-81379 München, Germany \\ ${ }^{4}$ RUAG Schweiz AG, RUAG Space, CH-8052 Zürich, Switzerland \\ ${ }^{5}$ MUSC, DLR, D-51147 Cologne, Germany \\ ${ }^{6}$ ESA ESTEC, Noordwijk, The Netherlands
}

\begin{abstract}
EXPOSE-R flew as the second of the European Space Agency (ESA) EXPOSE multi-user facilities on the International Space Station. During the mission on the external URM-D platform of the Zvezda service module, samples of eight international astrobiology experiments selected by ESA and one Russian guest experiment were exposed to low Earth orbit space parameters from March 10th, 2009 to January 21st, 2011. EXPOSE-R accommodated a total of 1220 samples for exposure to selected space conditions and combinations, including space vacuum, temperature cycles through $273 \mathrm{~K}$, cosmic radiation, solar electromagnetic radiation at $>110,>170$ or $>200 \mathrm{~nm}$ at various fluences up to $\mathrm{GJ} \mathrm{m}^{-2}$. Samples ranged from chemical compounds via unicellular organisms and multicellular mosquito larvae and seeds to passive radiation dosimeters. Additionally, one active radiation measurement instrument was accommodated on EXPOSE-R and commanded from ground in accordance with the facility itself. Data on ultraviolet radiation, cosmic radiation and temperature were measured every $10 \mathrm{~s}$ and downlinked by telemetry and data carrier every few months. The EXPOSE-R trays and samples returned to Earth on March 9th, 2011 with Shuttle flight, Space Transportation System (STS)-133/ULF 5, Discovery, after successful total mission duration of 27 months in space. The samples were analysed in the individual investigators laboratories. A parallel Mission Ground Reference experiment was performed on ground with a parallel set of hardware and samples under simulated space conditions following to the data transmitted from the flight mission.
\end{abstract}

Received 17 April 2014, accepted 6 June 2014, first published online 28 August 2014

Key words: astrobiology, exposure facility, external platform, International Space Station (ISS), space mission, space parameters.

\section{Introduction}

The EXPOSE multiuser facilities of the European Space Agency (ESA), mounted on external platforms of the International Space Station (ISS), provided long-term exposure of a variety of different astrobiology samples to selected parameters of outer space. They were developed by ESA, based on an advice of the ESA study team 'Exobiology Radiation Assembly (ERA) Follow-on Scientific Study' (ESA Contract no. 8116/88/F/BZ (SC) (Horneck et al. 1988)).

The EXPOSE missions continue a series of astrobiological space experiments in outer space and in low Earth orbit (LEO) that have been performed since the early 1970s (Bücker et al. 1974) and that were supported by space agencies in the USA, Europe and Russia. Inorganic material, organic chemical compounds and small life forms were exposed to selected space conditions in retrievable and non-retrievable satellites as well as on the space stations. Those studies dealt with various aspects of astrobiology: (i) responses of organisms to the space environment (Horneck et al. 1984, 2010; Horneck \& Brack 1992; Horneck 1998; Sancho et al. 2007; Jönsson et al. 2008); (ii) processes of chemical evolution and the modification of complex organics and aromatic networks in outer space (Ehrenfreund \& Foing 1997) and (iii) role of interstellar, cometary and planetary chemistry in the origin of life (Kuzicheva \& Gontareva 2001, 2002; Cottin et al. 2008). EXPOSE-R was the second mission of the EXPOSE family (Rabbow et al. 2009) that fulfilled a successful mission on the ISS. The cube-like structure (Fig. 1) provides space for astrobiology samples, sensors, heating systems, electronics for data collection, storage, telemetry and telecommand, and mechanical and electronic interfaces to the ISS platform. The samples are accommodated in carriers stacked in four cavities, the compartments, of each of three trays. The compartments are covered by magnesium fluoride $\left(\mathrm{MgF}_{2}\right)$ or quartz optical windows and 


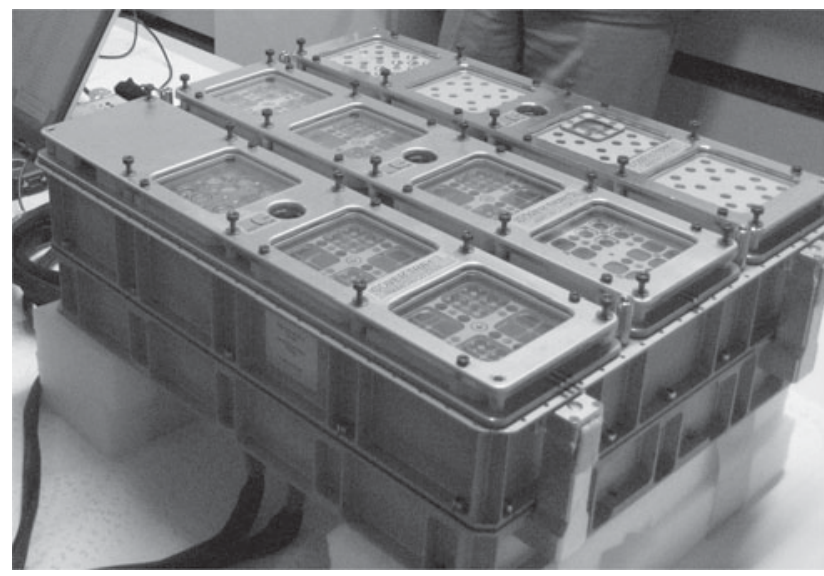

Fig. 1. Photograph of the EXPOSE-R facility at DLR after complete integration, ready for transport to Baikonur for launch. (Credit DLR).

neutral density filters, if appropriate. Samples located in top carriers are exposed to outer space conditions including solar extraterrestrial ultraviolet (UV) radiation, whereas those in bottom carriers experience similar exposure conditions except insolation.

EXPOSE-R was adapted on the Universal Workplace D (URM-D platform), one of the four external platforms of the Russian Zvezda-Module of the ISS (Fig. 2), whereas EXPOSE-E, the first EXPOSE mission, was accommodated on the European Technology Exposure Facility (EuTEF) on the starboard cone of the Columbus module (Rabbow et al. 2012). The EXPOSE-E mission already provided a wealth of results from the biological experiments (Horneck et al. 2012; Moeller et al. 2012; Nicholson et al. 2012; Onofri et al. 2012; Tepfer et al. 2012; Vaishampayan et al. 2012; Wassmann et al. 2012) as well as from the organic chemical experiments (Bertrand et al. 2012; Cottin et al. 2012; Noblet et al. 2012).

The launch of the first EXPOSE mission, originally planned for 2002, was postponed several times. Reasons were among others the Challenger (Space Shuttle flight, Space Transportation System (STS) 51-L) accident and delays in the delivery of ISS structures, which required re-planning of the EXPOSE missions by ESA. Finally EXPOSE-R was launched as the second EXPOSE mission in November 2008 to the ISS. Currently, the third EXPOSE mission EXPOSE-R2 is planned, to be flown in 2014/2015 again on the Russian Zvezda module for 1-1.5 years with four experiments selected by ESA and one from the Russian Federation State Research Center Institute of Biomedical Problems (IBMP) in Moscow, Russia.

Here, we present the technical and operational details of the EXPOSE-R mission. Results of the experiments participating in the EXPOSE-R mission are reported by the experimenters individually in this issue (Bérces et al. 2014; Berger et al. 2014; Bertrand et al. 2014; Bryce et al. 2014; Bryson et al. 2014; Carrasco et al. 2014; Cottin et al. 2014; Dachev et al. 2014; Mancinelli et al. 2014; Neuberger et al. 2014; Novikova et al. 2014; Panitz et al. 2014; Vergne et al. 2014).

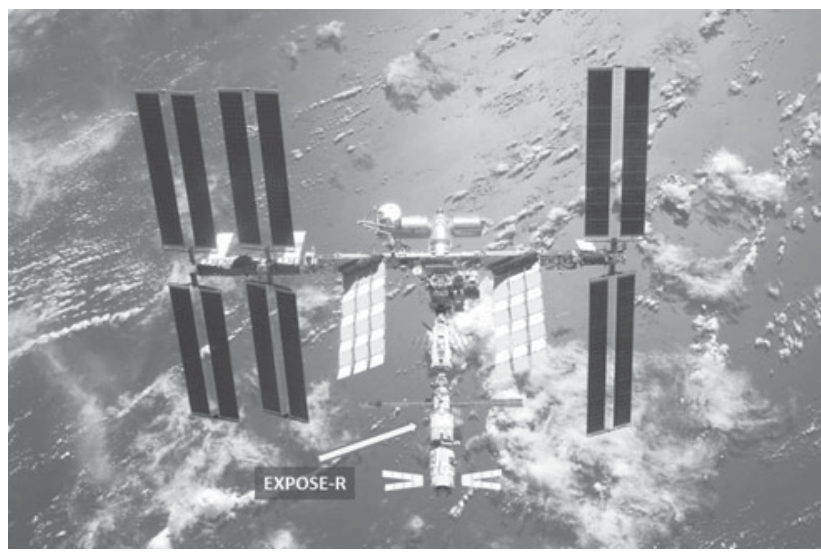

Fig. 2. Position of EXPOSE-R on the port side of the Zvezda module on the ISS (Credit NASA, adapted).

\section{EXPOSE-R experiments}

\section{Biological experiments}

In response to an ESA Announcement of Opportunities in 1996 for Externally Mounted Payloads during the Early Space Station Utilization Phase (ESA SP 1201: http://www.esa. int/esapub/sp/sp1201.htm) a multidisciplinary group of experts gathered to form a consortium with the aim to study the Responses of Organisms to Space Environment (ROSE consortium). Main research objectives were:

- Study of the photobiological/photobiochemical processes in the simulated climate of planets.

- Study of the probabilities and limitations for life to be distributed among the bodies of our Solar System.

After peer review of the submitted proposals, six experiments of the ROSE consortium were selected for flight (Table 1) (Bérces et al. 2014; Bryce et al. 2014; Mancinelli et al. 2014; Neuberger et al. 2014; Panitz et al. 2014). This set of biological experiments was later expanded by a Russian experiment provided by the IBMP in Moscow, IBMP and by SEEDS as part of the chemical experiment AMINO.

\section{Chemical experiments}

The two chemical experiments of the EXPOSE-R mission were designed to use the environment of outer space, especially the highly energetic solar extreme UV radiation, to study processes of chemical evolution (Table 1). Emphasis was laid on the study of the photochemical stability of complex organic compounds, analogues to those detected in the interstellar medium and in circumstellar clouds (Bryson et al. 2014), as well as in comets and the atmosphere of Saturn's moon Titan (Carrasco et al. 2014; Cottin et al. 2014). Furthermore, the stability of biomolecules, such as amino acids and RNA, under solar UV radiation was studied (Bertrand et al. 2014; Vergne et al. 2014).

\section{Radiation dosimetry}

To provide information about the time variation of the solar electromagnetic radiation (especially in the UV range) and 
Table 1. Experiments flown on the EXPOSE-R mission (Cottin 2011)

\begin{tabular}{|c|c|c|c|c|}
\hline Research field & Experiment name & Team leader (s) & Assay system & Topic of research \\
\hline \multirow[t]{8}{*}{ Biology } & ROSE 1/ENDO & $\begin{array}{l}\text { D.D. Wynn-Williams } \dagger / C \text {. Cockell } \\
\text { (UK) }\end{array}$ & Cyanobacteria: Chroococcidiopsis & $\begin{array}{l}\text { Study of the impact of extraterrestrial UV radiation on } \\
\text { microbial primary producers }\end{array}$ \\
\hline & ROSE 2/OSMO & R.L. Mancinelli (USA) & $\begin{array}{l}\text { Halobacteria: } \\
\text { Halorubrum chaoviatoris } \\
\text { Cyanobacteria: Synechococcus }\end{array}$ & $\begin{array}{l}\text { Study of the protective effects of gypsum-halite crusts } \\
\text { on enclosed osmophilic microorganisms }\end{array}$ \\
\hline & ROSE 3/SPORES & G. Horneck (DE) & $\begin{array}{l}\text { Bacterial spores: } \\
\text { Bacillus subtilis } \\
\text { Fungal spores: Trichoderma longibrachiatum } \\
\text { Fern spores: Athyrium filix-femina }\end{array}$ & $\begin{array}{l}\text { Study the protection of spores by meteorite material against } \\
\text { space conditions: UV, vacuum, ionizing radiation }\end{array}$ \\
\hline & ROSE 4/PHOTO & J. Cadet (FR) & Bacterial spores: Bacillus subtilis & $\begin{array}{l}\text { Study of the photoproducts resulting from exposure of } \\
\text { bacterial spores to solar extraterrestrial UV radiation }\end{array}$ \\
\hline & ROSE 5/ SUBTIL & N. Munakata (JP) & Bacterial spores: Bacillus subtilis & $\begin{array}{l}\text { Study of the mutational spectra induced by spce vacuum and } \\
\text { solar UV radiation }\end{array}$ \\
\hline & ROSE 8/ PUR & G. Ronto (HU) & Uracil Bacteriophage $\mathrm{T} 7$ & $\begin{array}{l}\text { Study of the biologically effective dose of solar extraterrestrial } \\
\text { UV radiation by biological dosimetry }\end{array}$ \\
\hline & IBMP & V. Sychev (RU) & $\begin{array}{l}\text { Bacillus spores: } \\
\text { Bacillus subtilis } \\
\text { Bacillus pumilus } \\
\text { Bacillus licheniformis } \\
\text { Fungus spores: } \\
\text { Aspergillus sydowi } \\
\text { Aspergillus versicolor } \\
\text { Penicillium aurantio-griseum } \\
\text { Penicillium expansum } \\
\text { Geomyces pannorum } \\
\text { Plant seeds: } \\
\text { Arabiposis thaliana } \\
\text { Lycopersicum esculentum } \\
\text { Raphanus sativus } \\
\text { Midge larvae: } \\
\text { Polypedilum vanderplanki } \\
\text { Crab eggs: } \\
\text { Artemia salina } \\
\text { Streptocephalus torvicornis } \\
\text { Eucypris species } \\
\text { Daphnia magna }\end{array}$ & $\begin{array}{l}\text { Study the responses of various resistant organisms to space } \\
\text { conditions }\end{array}$ \\
\hline & SEEDS & D. Tepfer (FR) & Plant seeds Arabidopsis thaliana & Study of the resistance of seeds to the space environment \\
\hline \multirow[t]{2}{*}{ Chemistry } & AMINO & A. Brack/H. Cottin (FR) & $\begin{array}{l}\text { Amino acids } \\
\text { RNA fragments } \\
\text { Samples relevant to cometary and Titan } \\
\text { chemistry }\end{array}$ & Study of photochemical processing in outer space \\
\hline & ORGANIC & P. Ehrenfreund (NL) & Carbon polymers & Study of the evolution of organic matter in space (PAHs) \\
\hline \multirow[t]{2}{*}{$\begin{array}{l}\text { Radiation } \\
\text { dosimetry }\end{array}$} & R3DR & D. Haeder (DE)/T. Dachev (BG) & Optical sensors/silicon detector & $\begin{array}{l}\text { Study of the time profile of solar electromagnetic radiation } \\
\text { and cosmic ionizing radiation during the mission }\end{array}$ \\
\hline & DOSIS & T. Berger (DE) & Thermoluminescence dosimeter & $\begin{array}{l}\text { Study of the radiation exposure (total mission dose) } \\
\text { at the sample site }\end{array}$ \\
\hline
\end{tabular}


the galactic cosmic radiation, the EXPOSE-R payload accommodated the Radiation Risks Radiometer-Dosimeter (R3DR) (Table 1). Its primary role was to monitor the time profile of the radiation exposure during the EXPOSE-R mission (Dachev et al. 2014). In addition, thermoluminescence dosimeters were located in close neighbourhood of the test samples, to determine the ionizing radiation dose received by individual test objects (Berger et al. 2014).

\section{EXPOSE-R payload}

\section{EXPOSE-R space flight hardware}

The family of EXPOSE facilities is based on the heritage of exposure platforms used during previous Space Shuttle missions (SpaceLab 1 (SL1) and Deutschland 2 (D2)) and of the ERA of the European Retrievable Carrier (EURECA) mission (Rabbow et al. 2009, 2012; Horneck 2011). EXPOSE$\mathrm{R}$ consists of a box-shaped core facility, the so-called 'monoblock' (Fig. 1) with the dimensions $480 \mathrm{~mm} \times 390 \mathrm{~mm} \times$ $140 \mathrm{~mm}$ (length $\times$ width $\times$ height) and a mass of $44 \mathrm{~kg}$. This monoblock accommodates the auxiliary electronics including heating systems. In the upper part, three exposure trays, each $466 \mathrm{~mm} \times 120 \mathrm{~mm} \times 88.5 \mathrm{~mm} \quad$ (length $\times$ width $\times$ height $)$ and each of a mass of $4-5 \mathrm{~kg}$ were integrated. Each tray was equipped with a handling mechanism to allow astronauts to extract the trays from the monoblock during an extravehicular activity (EVA) at the end of the EXPOSE-R mission. Beneath each tray, three temperature sensors (eight of the type $\mathrm{S} 651$ PDY 24 A by MINCO EC AG, Wil, SG, Switzerland and one AD590 temperature sensor in tray 3) were located to provide data on the spatial and temporal temperature gradients during the EXPOSE-R mission. Their data plus those from the temperature reference point provided the basis for temperature regulations of EXPOSE-R: at temperatures increasing above $53{ }^{\circ} \mathrm{C}$ the electronics of EXPOSE-R were shut down to minimize further internal heating, while heating systems were activated at temperatures below $-25^{\circ} \mathrm{C}$ to keep EXPOSE-R electronics operating. All data were down linked by telemetry and saved on an on-board Personal Computer Memory Card International Association (PCMCIA) card to be downloaded regularly every few months. They provided the simulation parameters for the Mission Ground Reference (MGR) experiment (see below) and were made available to the investigators.

To provide data on the optical radiation environment of EXPOSE-R, four UV sensors (OEC UV Photodiode EPD280-0-0.3-C-D) were installed in the top part of the facility, one at each corner. In addition, one radiometer (Dexter $6 \mathrm{M}$ thin-film based thermopile detector) was mounted in close vicinity to the sensor UV3 (Fig. 3). These sensors were facilityprovided and complementary to the sensors of R3DR.

The experimental samples were accommodated in four rectangular cavities $(77 \mathrm{~mm} \times 77 \mathrm{~mm} \times 26 \mathrm{~mm})$ of each tray (Figs. 1 and 3). A total of 1220 samples were used: 1062 biological samples, 130 chemical samples and 28 passive dosimeter packages, plus the R3DR instrument (Table 1).

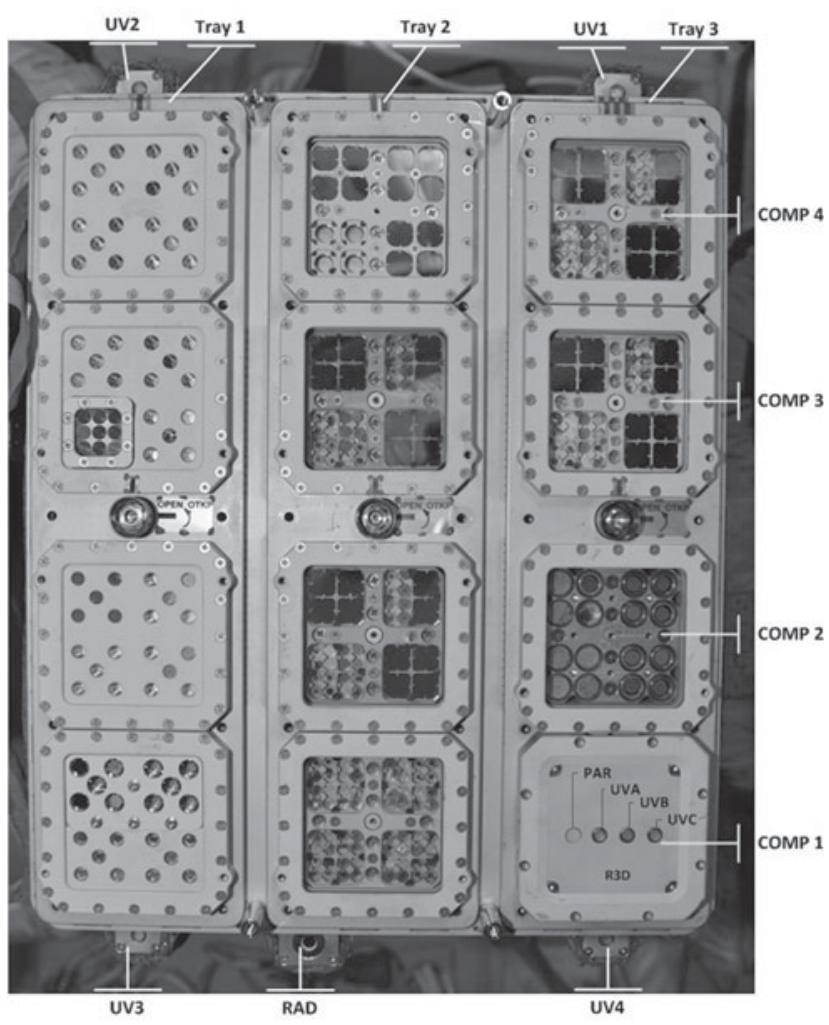

Fig. 3. Scheme of EXPOSE-R with trays, compartments, sensors and window arrangement.

Before launch, all compartments were filled with an argon atmosphere at an inner ambient pressure of $1023 \mathrm{hPa}$. During the mission, they provided two alternative pressure/atmosphere conditions (Table 2):

- Space vacuum: In this case, the compartment was connected by a venting line to a valve (PhiTec, Switzerland) for evacuation to space vacuum during the mission.

- Argon ambient pressure $(1023 \mathrm{hPa})$ : In this case, the compartment remained sealed keeping the inner ambient pressure $(1023 \mathrm{hPa})$ argon atmosphere.

To control the spectral insolation of the samples, the compartments were covered with different windows and optical filters (Table 2):

- $\mathrm{MgF}_{2}$ (MaTeck GmbH, Germany) windows, transmitting solar extraterrestrial electromagnetic radiation of $\lambda>110 \mathrm{~nm}$.

- Quartz glass windows (MaTeck GmbH, Germany, Wisag AG, Switzerland) transmitting solar radiation of $\lambda>170 \mathrm{~nm}$ (IBMP experiments).

- Quartz glass windows with an additional long pass cut off filter with $50 \%$ transmission at $216 \mathrm{~nm}$ (Wisag AG, Switzerland) resulting in a transmission of $\lambda>200 \mathrm{~nm}$.

In addition neutral density filters were used to attenuate the total transmitted fluence at sample site by $10^{-2}, 10^{-4}$ or $10^{-6}$. They were made either of $\mathrm{MgF}_{2}$ (MaTeck GmbH, Germany; Moltech GmbH, Germany) or of coated (Thin Film Physics AG, Switzerland) quartz (Moltech GmbH, Germany). 
Ionizing radiation was measured with passive radiation detectors in special cavities below the sample carrier stacks (Berger et al. 2014) and with the active R3DR instrument Dachev et al. 2014). EXPOSE-R heaters prevented a decrease of the temperature below $-25^{\circ} \mathrm{C}$.

\section{Experiment preparation}

\section{Experiment Verification Tests}

Prior to the EXPOSE-R mission, the environmental limits of the test systems with respect to temperature, pressure and UV radiation tolerances were determined during a preflight verification and test programme. These Experiment Verification Tests (EVTs) were conducted at the Deutsches Zentrum für Luft- und Raumfahrt (DLR), Institute of Aerospace Medicine, using their Planetary and Space Simulation facilities (PSI). The aim of the EVTs was: (i) to reach the final design of the EXPOSE facility according to the requirements by the different projects teams; (ii) to optimize the experimental design and pre- and post-flight procedure requirements of the different projects; and (iii) to obtain baseline data for the different projects.

The following EVTs were performed in the frame of EXPOSE-R:

- EXPOSE EVT Phase 1: 18.07-30.07.2002, with the aim to assess the resistance of the biological test samples to desiccation, vacuum and UV radiation and to define the dimensions and experimental setups for sample exposure.

- EXPOSE EVT Phase 2: 12.02-26.03.2003, with the aim to determine the permissible temperature range for the EXPOSE-R experiments and the effect of temperature fluctuations around the freezing point.

- EXPOSE EVT Phase 3/1+2: 23.10-12.11.2003+12.02.03.03.2004, with the aim to determine the optical filter arrangement for the flight experiment with regard to total expected fluence of solar polychromatic UV radiation during the mission and to determine the most suitable gas composition for the samples kept at atmospheric conditions.

- EXPOSE EVT Phase 4/1+2: 30.05-23.06.2005+29.1119.12.2005, with the aim to determine the optical filter arrangement with regards to solar vacuum UV radiation and to doses expected during the mission.

- EXPOSE EVT Phase 5/1+2: 14.07-23.08.2006, with the aim to determine the optical filter arrangement for the whole spectrum of extraterrestrial solar UV radiation.

The data collected during the different EVTs were used to define the optical filter arrangement requirements of EXPOSE-R and to optimize the sample distribution plan concerning the different exposure conditions.

\section{Experiment Sequence Test}

Subsequent to the EVTs, an EXPOSE-R Experiment Sequence Test (EST) was performed from 31.08. to 24.09.2007. Its objective was to perform a simulation of the flight mission with the flight hardware and including all operations as realistically as possible. This included sample preparation, transport to the DLR, sample integration, representative test runs of the space exposure conditions, disintegration of samples, overall time schedule of experiment run and assembly and disassembly procedure, delivery to investigators and sample analysis.

\section{Experiment assembly}

Four months before flight, the different samples were accommodated in the 12 compartments of the three trays according to their individual requirements of applied space parameters (Table 2). Two or three stacked sample carriers per compartment accommodated samples to be irradiated during the mission in the top carrier, and the corresponding dark samples in the middle and bottom carriers.

Tray 1 was mainly reserved for the two organic chemical experiments: AMINO and ORGANIC (Tables 1 and 2). Individual sample cells were used that were each covered with a $1 \mathrm{~mm}$ thick $\mathrm{MgF}_{2}$ window.

The ROSE-experiments (Table 1) were accommodated in trays 2 and 3 (Table 2). For the experiments ROSE 1-5 three sample carriers with 64 sample wells each were stacked in each compartment: a top carrier for the UV-exposed samples and two carriers below for samples kept in the dark but experiencing all other parameters of outer space. Thermoluminescence dosimeters (TLD) were installed below the lower dark sample carriers in cavities of seven compartments of the trays 2 and 3 (experiment DOSIS, Table 1). ROSE 8 used its own sample carriers with 16 sample wells: one top carrier for UV exposure and one beneath for the dark samples. The biological experiments of IBMP were accommodated in trays 1 and 2 (Table 2). The active radiation dosimetry instrument R3DR (Table 1) occupied one compartment in tray 3 (Table 2). Except for the compartment with the R3DR instrument, all compartments of trays 2 and 3 were covered by an $8 \mathrm{~mm}$ thick top window of either $\mathrm{MgF}_{2}$ or quartz. The window arrangement in the trays and compartments and the location of the sensors attached to the monoblock are shown in Fig. 3.

Samples were integrated in an inert argon atmosphere at $102 \mathrm{kPa}$ and valves were closed. Closed compartments not connected to the venting line kept this captured argon gas for the whole mission. In addition to the flight unit, an identical set of samples (biology and chemistry) was accommodated in identical arrangements in three further trays to serve for the MGR (see below).

The fully accommodated EXPOSE-R payload before transport to the launch site in Baikonur is shown in Fig. 1.

\section{EXPOSE-R space flight mission}

\section{EXPOSE-R mission overview}

On November 26th, 2008, the fully accommodated EXPOSE$\mathrm{R}$ facility covered with a removable, transparent top window protection was launched on-board of the $31 \mathrm{P}$ Progress launcher from Baikonur, Kasakhstan, to the ISS. 
Table 2. Accouterments of the different compartments of EXPOSE-R, calculated external total mission fluence (100 $\mathrm{nm}-1 \mathrm{~mm})$ of solar electromagnetic radiation and calculated UV fluence at sample site (averaged over all samples beneath the same window and filter system in the compartment)

\begin{tabular}{|c|c|c|c|c|c|c|c|c|c|}
\hline Tray no. & Comp. no. & Experiments & $\begin{array}{l}\text { Compartment } \\
\text { type }\end{array}$ & Pressure/atmosphere & $\begin{array}{l}\text { External fluence at } \\
>110 \mathrm{~nm}\left(\mathrm{GJ} \mathrm{m}^{-2}\right)\end{array}$ & Window & $\begin{array}{l}\text { Wavelength } \\
\text { range }(\mathrm{nm})\end{array}$ & $\begin{array}{l}\text { Filter } \\
\text { transmission (\%) }\end{array}$ & $\begin{array}{l}\text { UV fluence at sample } \\
\text { site }\left(\mathrm{MJ} \mathrm{m}^{-2}\right)\end{array}$ \\
\hline \multirow[t]{5}{*}{1} & \multirow[t]{2}{*}{1} & \multirow[t]{2}{*}{ AMINO IBMP } & \multirow[t]{2}{*}{ Vented } & \multirow[t]{2}{*}{$10^{-4}-10^{-7} \mathrm{~Pa}^{*}$} & \multirow[t]{2}{*}{17.3} & $\mathrm{MgF}_{2}$ & $>110$ & \multirow[t]{2}{*}{100} & $\begin{array}{c}1043.2 \pm 0 \\
914.8 \pm 1.8\end{array}$ \\
\hline & & & & & & Quartz & $>170$ & & \\
\hline & 2 & AMINO & Vented & $10^{-4}-10^{-7} \mathrm{~Pa}^{*}$ & 17.2 & $\mathrm{MgF}_{2}$ & $>110$ & 100 & $1020.0 \pm 1.7$ \\
\hline & 3 & ORGANIC SEEDS & Vented & $10^{-4}-10^{-7} \mathrm{~Pa}^{*}$ & 17.0 & $\mathrm{MgF}_{2}$ & $>110$ & 100 & $\begin{array}{l}1008.3 \pm 1.7 \\
1098.1 \pm 43.1\end{array}$ \\
\hline & 4 & ORGANIC & Closed & $102 \mathrm{kPa} /$ argon & 16.7 & $\mathrm{MgF}_{2}$ & $>110$ & $\begin{array}{l}100 \\
100\end{array}$ & $993.4 \pm 1.7$ \\
\hline \multirow[t]{4}{*}{2} & 1 & IBMP & Vented & $10^{-4}-10^{-7} \mathrm{~Pa}^{*}$ & 17.3 & Quartz & $>170$ & 100 & $547.4 \pm 65.9$ \\
\hline & 2 & ROSE $1,2,3,4,5$ & Vented & $10^{-4}-10^{-7} \mathrm{~Pa}^{*}$ & 17.2 & Quartz & $>200$ & $\begin{array}{l}100 \\
1 \\
001\end{array}$ & $\begin{array}{l}506.1 \pm 85.1 \\
4.8 \pm 0.9 \\
46 \times 10^{-2}+75 \times 10^{-3}\end{array}$ \\
\hline & 3 & ROSE $1,2,3,4,5$ & Vented & $10^{-4}-10^{-7} \mathrm{~Pa}^{*}$ & 17.0 & $\mathrm{MgF}_{2}$ & $>110$ & $\begin{array}{l}0.01 \\
100 \\
1 \\
0.01\end{array}$ & $\begin{array}{l}4.6 \times 10^{-2} \pm 7.5 \times 10^{-3} \\
576.4 \pm 97.9 \\
5.4 \pm 1.0 \\
5.3 \times 10^{-2} \pm 8.37 \times 10^{-3}\end{array}$ \\
\hline & 4 & ROSE 8 & Closed & $102 \mathrm{kPa} /$ argon & 16.7 & $\mathrm{MgF}_{2}$ & $>110$ & $\begin{array}{l}100 \\
1 \\
0.01 \\
0.0001\end{array}$ & $\begin{array}{l}849.1 \pm 126.1 \\
8.5 \pm 1.0 \\
8.0 \times 10^{-2} \pm 1.2 \times 10^{-2} \\
8.4 \times 10^{-4} \pm 1.1 \times 10^{-4}\end{array}$ \\
\hline 3 & 1 & R3D & Closed & $\mathrm{n} / \mathrm{a}$ & 17.4 & $\mathrm{n} / \mathrm{a}$ & $\mathrm{n} / \mathrm{a}$ & $\mathrm{n} / \mathrm{a}$ & \\
\hline & 2 & ROSE $1,2,3$ & Vented & $10^{-4}-10^{-7} \mathrm{~Pa}^{*}$ & 17.2 & $\mathrm{MgF}_{2}$ & $>110$ & 100 & $460.0 \pm 78.6$ \\
\hline & 3 & ROSE $1,2,3,4,5$ & Closed & $102 \mathrm{kPa} /$ argon & 16.9 & $\mathrm{MgF}_{2}$ & $>110$ & 100 & $748.5 \pm 127.1$ \\
\hline & & & & & & & & $\begin{array}{l}1 \\
0.01\end{array}$ & $\begin{array}{l}7.0 \pm 1.3 \\
6.8 \times 10^{-2} \pm 1.1 \times 10^{-2}\end{array}$ \\
\hline & 4 & ROSE $1,2,3,4,5$ & Closed & $102 \mathrm{kPa} /$ argon & 16.6 & Quartz & $>200 \mathrm{~nm}$ & 100 & $613.9 \pm 103.6$ \\
\hline & & & & & & & & 1 & $5.9 \pm 1.0$ \\
\hline & & & & & & & & 0.01 & $5.7 \times 10^{-2} \pm 8.8 \times 10^{-3}$ \\
\hline
\end{tabular}

* Average outside pressure during the mission. Data derived from MEDET for EXPOSE-E, personal communication René Demets, ESA. 
After docking 4 days later, the facility was transported into the Russian module, examined for damage and stored. On December 23rd, 2008, the facility was transported by an EVA to the external URM-D platform, attached and connected. Power connection of EXPOSE-R could not be confirmed. Therefore, it was returned during the same EVA back into the ISS and stored again for trouble shooting.

After a second EVA (Fig. 4), EXPOSE-R was commissioned and started successfully on March 11th, 2009. Valves were opened by telecommand to evacuate the connected compartments to space vacuum. The first received data sets confirmed the valve open status and reported nominal health status of EXPOSE-R.

On June 25th, 2009, the on-board computer connecting the external facility to the ISS inside and to ground broke. Measured environmental data from EXPOSE-R could no longer be stored and were lost. The computer was exchanged on December 28th, 2009, and data retrieved nominal until February 12th, 2010, when a BRI (Russian Router Ethernet) exchange and cable reconnection was performed. On March 22nd, 2010, the system was recovered and the mission was nominal. On January 21st, 2011, the end of the mission was marked by the telecommand to close the three valves. After return of the whole monoblock of EXPOSE-R into the ISS by EVA, the astronauts wiped the outside of EXPOSE-R to remove any possible toxic substances for safety reasons. On January 28th, 2011, the three trays were de-integrated and returned to ground with one of the last Shuttle flights STS-133/ ULF 5, Discovery. It landed at Kennedy Space Center in Florida, USA, on March 9th, 2011 and only 3 days later, on March 12th, 2011, the three trays arrived at DLR Cologne, Germany, for sample de-integration and distribution to the team leaders.

The total mission duration from launch to landing was 833 days, with an exposure duration in outer space of 682 days. The complete mission, from tray closure after sample integration at the DLR to tray opening was 950 days.

A mission overview is given in Table 3 .

\section{EXPOSE- $R$ mission data}

EXPOSE-R was programmed to collect environmental data every $10 \mathrm{~s}$ for the mission exposure duration from the nine temperature sensors, the four UV sensors, the radiometer and the R3DR experiment. They were transmitted to ground regularly, complemented by health status and status data of the three valves via TsUP (Mission Control Center Moscow, MCC-M) to the Microgravity User Support Center (MUSC) at DLR, Cologne, Germany, where the data were archived, analysed and provided to the team leaders on an ftp server. Data were open for public visualized on the webpage http://www.go.dlr.de/musc/expose/telemetrie.php. In addition, the PCMCIA cards with the stored data were regularly downloaded.

Due to the extended period when no data could be stored on the on-board computer (Table 3 ), a total mission environmental profile could not be provided. Therefore, RedShift was contracted to model and calculate the overall total UV

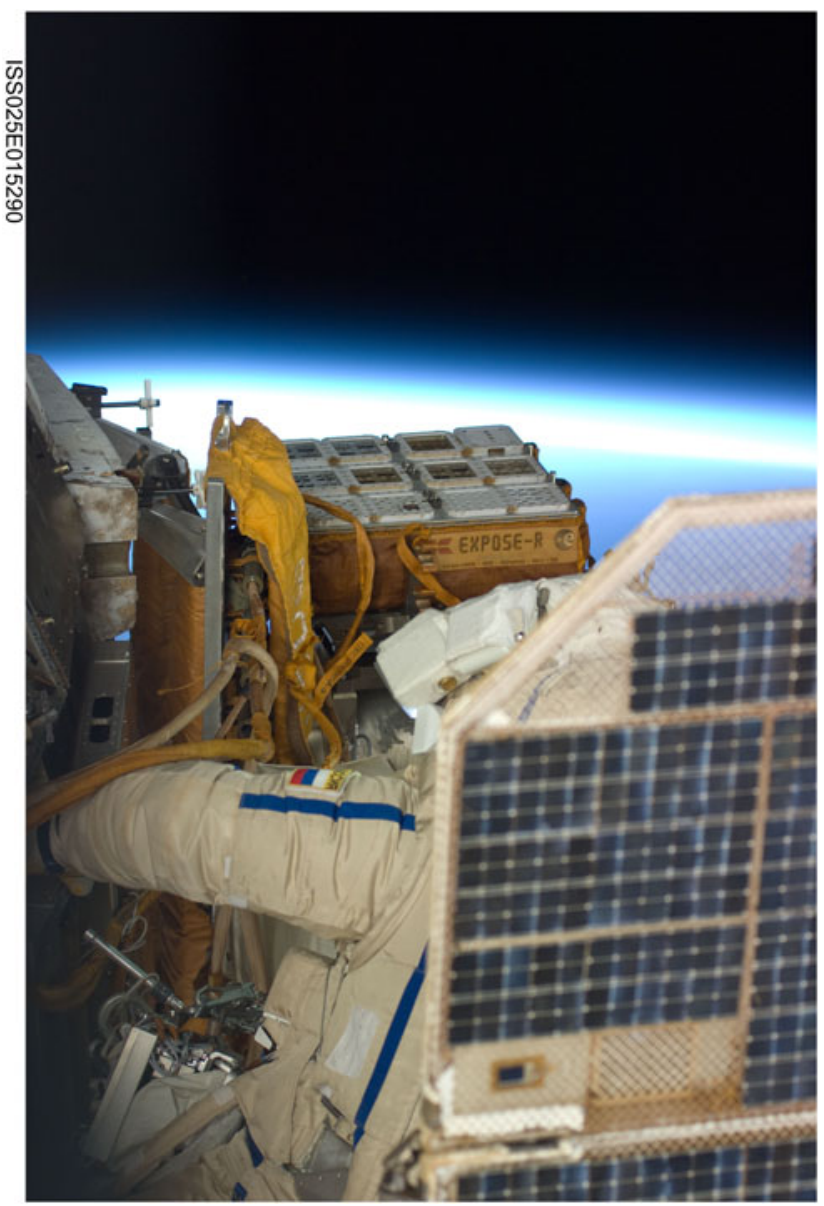

Fig. 4. Installation of EXPOSE-R by EVA at the URM-D platform of the Zvezda module of the ISS. Tray 1 is on top of the picture, compartments 1 are on the right side, and compartments 4 on the left side.

radiation and temperature of the facility for the EXPOSE-R mission. Including additional smaller data gaps, they estimated a total loss of measured environmental data of $42 \%$. The calculated data from RedShift became the basis for the on ground irradiation during the mission simulating MGR experiment performed in the PSI at DLR in Cologne and for the experiment analysis and interpretation.

\section{EXPOSE-R mission environment}

\section{Solar UV irradiation}

EXPOSE-R was equipped with four house-keeping UV sensors located in each corner of the facility, one broad band radiometer (Fig. 3) and the R3DR experiment, that measured the solar spectral UV and VIS irradiances every $10 \mathrm{~s}$ to determine the overall mission fluence and information on the fluctuations of the UV-irradiance during the EXPOSE-R mission as a consequence of ISS flight attitude and orbit. Data were transmitted by telemetry to the ground facilities. Due to various off-nominal events that interrupted the data acquisition (see above), and the consequent severe loss of environmental data, it was impossible to determine the total 
Table 3. EXPOSE-R2 Mission timeline and durations

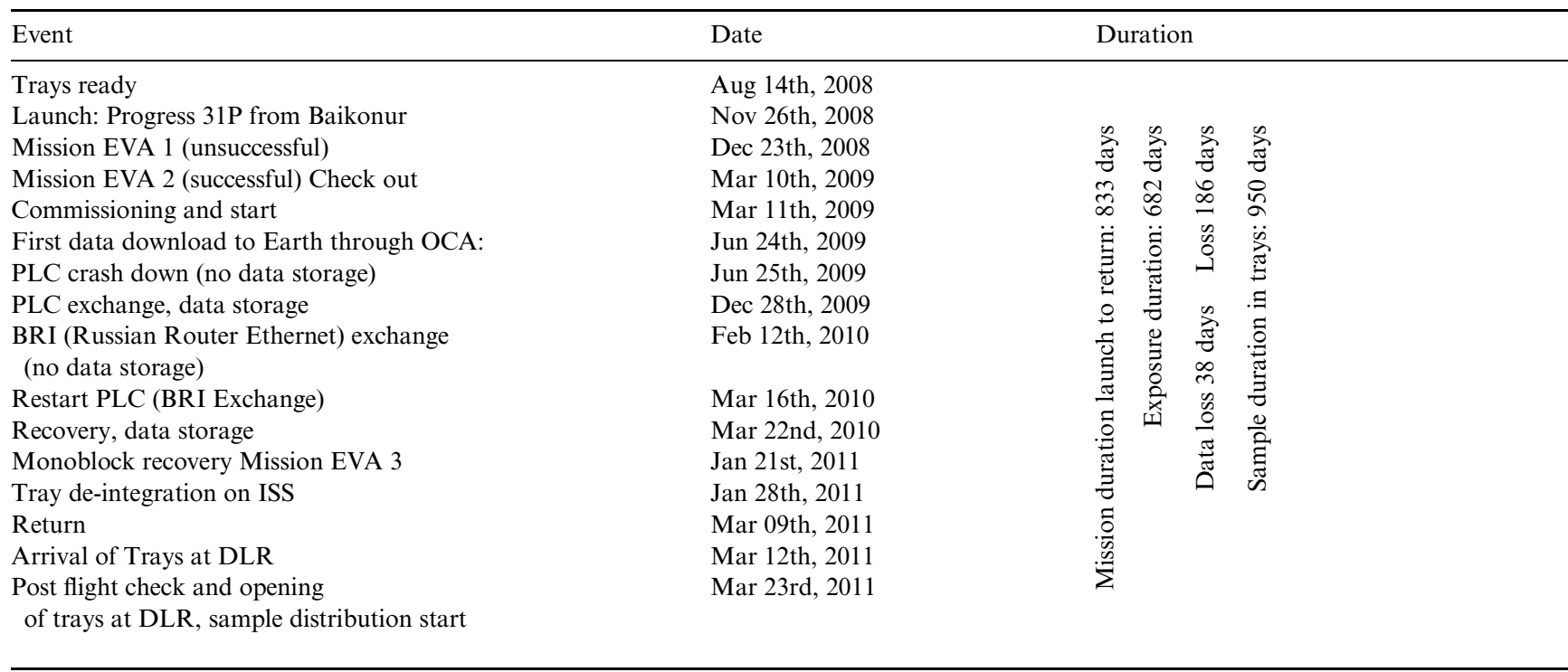

UV fluence received during the mission from the transmitted data. The only way out was model calculations to assess the total UV fluences at the sample sites, which were performed by the RedShift Design and Engineering BVBA, Belgium (Beuselinck \& van Bavinchove 2011). Shadow maps were calculated for EXPOSE-R from available ISS mission flight data of the ISS position in its orbit, ISS attitude, joint angles defining positions of solar arrays and radiators, evolution of the ISS configuration, and information of visiting spacecrafts and their docking positions (Space Shuttle, Soyuz, Progress, Automated Transfer Vehicle (ATV)). From these calculations, the resulting total insolation in Solar Constant hours ( $\mathrm{SCh}$ ) was calculated for each sample in the 12 compartments of EXPOSE-R and for a variety of fields of view, taking the sample geometry and optical filter combinations into account (Table 2). RedShift calculated the corresponding fluences for UVA, UVB, UVC and PAR as well as for the UV wavelength band from 200 to $400 \mathrm{~nm}$ and the full-UV range from $100 \mathrm{~nm}$ to $1 \mathrm{~mm}$ wavelength using the extraterrestrial solar UV data from SORCE http://lasp.colorado.edu/sorce/index.htm. Due to various shadowing effects caused by the ISS geometry and attitude the calculated total mission fluence on the top surface of EXPOSE-R varied by up to $4.6 \%$. There was also a gradient of irradiance on each tray, increasing from compartments 4 to compartments 1 (Table 2), which was mainly due to shadowing by surrounding equipment (Fig. 4). RedShift considered in their calculation also the window contamination (see below and Demets et al. 2014).

These calculated irradiances were also used to define the fluences for the MGR irradiation with the UV solar simulator (SOL2000, Dr Hönle GmbH) (Table 4).

\section{Top window contamination}

Before integration, all top windows were analysed with respect to surface integrity (safety considerations) and transmission properties. Transmission of the $\mathrm{MgF}_{2}$ and quartz top windows ranged about 91 and $90 \%$, respectively as measured with a Hitachi U3310 double monochromator photometer in the wavelength range $200-600 \mathrm{~nm}$ at DLR and determined by the payload developer Kayser-Threde $\mathrm{GmbH}$, Munich, Gemany (KT) and RUAG Space, Zurich, Switzerland.

Already after return of the EXPOSE-R facility into the ISS, pictures taken by the astronauts revealed a partial severe brownish colouring of the top windows (Fig. 5). Closer inspection after return of the trays to ground showed that windows covering vented compartments were contaminated with a transmission decreasing layer (Table 5). This contamination was mainly found at the inside of the windows. Windows on top of closed compartments did not show any contamination and therefore retained their high transparency (Table 5). The contamination was investigated by RUAG and at ESTEC. The loss of transmission was considered in the calculated values for the mission fluences by RedShift, using the mission-average transmittance of the windows, based on pre-flight transmittance and post-flight (degraded) transmittance.

It could not be determined if there was an outside contamination too, and if the lack of substantial detectable contamination at the outside of the windows could be explained by the fact that after the end of the mission and return of EXPOSE-R to the inside of the ISS, the whole facility was thoroughly cleaned by the astronauts with wipes impregnated with a $3 \%$ hydrogen peroxide solution to reduce potential toxic substances. This procedure is required by ISS safety policy. More information and full spectra of all large windows are provided in Demets et al. 2014.

A close inspection of the top windows by RUAG (Switzerland) additionally revealed that the:

- quartz window covering tray 2 compartment 1 showed pitting and a pattern consistent with recrystallization of the silica. 
Table 4. $U V(200-400 \mathrm{~nm})$ fluences from a solar simulator (Dr Hönle GmbH solar simulator SOL2000) applied to the different compartments of the three ground trays during the $M G R$ of EXPOSE-R

\begin{tabular}{llll}
\hline Tray & Compartment & Experiments & $\begin{array}{c}\text { UV }(200-400 \mathrm{~nm}) \\
\text { fluence }\left(\mathrm{MJ} \mathrm{m}^{-2}\right)\end{array}$ \\
\hline 1 & $1,2,3,4$ & AMINO, IBMP, & 1130 \\
& & ORGANIC, SEEDS & \\
2 & 1 & IBMP & 834 \\
& 2,3 & ROSE 1,2,3,4,5 & 859 \\
& 4 & ROSE 8 & 1070 \\
3 & 2 & ROSE $1,2,3$ & 904 \\
& 3,4 & ROSE 1,2,3,4,5 & 904 \\
\hline
\end{tabular}

- $\mathrm{MgF}_{2}$ windows of tray 2 compartment 3 and tray 3 compartment 2 showed scuff marks on their inner surface.

\section{Micrometeorites}

A considerable number of local micrometeorite impacts were registered in several top windows:

- Quartz window in tray 2, on top of compartment 1;

- Quartz window in tray 2, on top of compartment 2 (Fig. 6);

- Quartz window in tray 3, on top of compartment 4;

- $\mathrm{MgF}_{2}$ window in tray 2, on top of compartment 3;

- $\mathrm{MgF}_{2}$ window in tray 3, on top of compartment 2.

However, the cracks did not propagate beyond the impacted region. No substantial increase in the number or extension of flaws was detected in the windows other than the increase brought about by micrometeorite or debris impact (Pereira \& Jaramillo 2011).

\section{Cosmic radiation exposure}

Dosimetry of the ionizing radiation was performed with two experiments: the active instrument R3DR (Dachev et al. 2014) and the passive detectors of the DOSIS experiment (Berger et al. 2014). The passive dosimeters allowed an estimation of the total mission dose and its distribution over the EXPOSE-R facility. TLDs were analysed after retrieval. The total mission dose ranged from 225 to $320 \mathrm{mGy}$ (Berger et al. 2014).

R3DR data of the averaged absorbed daily dose rates of the three essential components of the radiation field encountered at the orbit of the ISS were determined when data were available: $506 \mu \mathrm{Gy} \mathrm{day}^{-1}$ due to the protons of the South Atlantic Anomaly of the radiation belts, $81.4 \mu \mathrm{Gy} \mathrm{day}^{-1}$ due to galactic cosmic rays, and $89 \mu \mathrm{Gy} \mathrm{day}^{-1}$ caused by the energetic electrons from the Outer Radiation Belt (Dachev et al. 2014). Because the R3DR data storage depended on the on-board computer, it suffered data loss due the computer failure and exchange.

\section{Temperature}

A total of nine temperature sensors mounted below the three trays monitored the temperature of the sample accommodating hardware during the mission. Overall measured temperature fluctuated between +49.47 and $-24.65^{\circ} \mathrm{C}$ with a

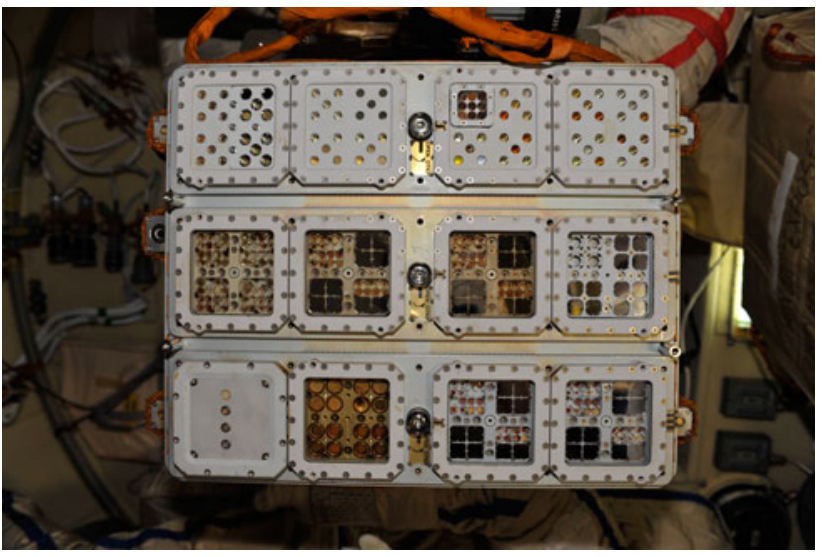

Fig. 5. Top view photo of EXPOSE-R taken by the astronauts after return to the ISS at the end of the EXPOSE-R mission (Credit NASA).

slow oscillation rhythm due to the position of the orbital plane of the ISS w.r.t. the Sun and an overlying faster rhythm of roughly $91 \mathrm{~min}$ periodicity, resulting from the day/night transmissions during each orbital loop. The measured temperature gradient over the EXPOSE-R facility ranged from $+49.47^{\circ} \mathrm{C}$ at tray 3 compartment 3 (sensor 3 ) to $+45.88^{\circ} \mathrm{C}$ at tray 1 compartment 1 (sensor 1) for the highest temperature measured on December 26th, 2010, and from $-24.65^{\circ} \mathrm{C}$ at tray 3 compartment 2 (sensor 2) to $-19.24^{\circ} \mathrm{C}$ at tray 1 compartment 3 (sensor 3 ) for the coldest time point, resulting in a temperature gradient of 3.59 and $5.41{ }^{\circ} \mathrm{C}$, respectively. These temperature data were used for the MGR as they became available by telemetry from the ISS.

Due to the extensive temperature data loss, RedShift calculated the overall mission temperatures. According to these simulation data, the average tray temperature ranged from -27 to $+46^{\circ} \mathrm{C}$ with a mission average temperature of $+19^{\circ} \mathrm{C}$. Analysis of the simulated average tray temperature shows $5690^{\circ} \mathrm{C}$-crossings, corresponding to 285 freeze-thaw cycles including 274 short-duration freeze-thaw cycles and 11 long-duration freeze periods.

In general, the calculated temperature data are in good accordance to the available measured data, but during some time periods the simulated temperature deviates significantly from the measured temperature by up to $10^{\circ} \mathrm{C}$. Reasons could be a typical loss of phase during simulated thermostat-controlled heater operation, inaccuracies in the solar irradiation simulation (caused by missing input data), changes in the EXPOSE-R power dissipation or changes in the environment (e.g. the Zvezda solar array position) (Beuselinck \& van Bavinchove 2011). However, comparison between simulated temperatures and telemetry data generally confirmed the validity of the simulation.

Space vacuum

EXPOSE-R was not equipped with pressure sensors for environmental pressure monitoring. Available sensors only verified a general pressure loss inside the trays after valve opening to confirm proper functioning of the valves 
Table 5. Transmission of windows of EXPOSE-R after the mission and that of unexposed reference windows (data for transmission at $200 \mathrm{~nm}$ from RUAG, Doc. Nr. EXR-TR-HT-010, issue 2, 2011, EXPOSE-R Post-flight Inspection of Windows and at $190 \mathrm{~nm}$ from $E S A$ )

\begin{tabular}{|c|c|c|c|c|c|}
\hline Tray & Compartment & Compartment type & Window & $\begin{array}{l}\text { Transmission at } \\
200 \mathrm{~nm}(\%)\end{array}$ & $\begin{array}{l}\text { Transmission at } \\
190 \mathrm{~nm}(\%)\end{array}$ \\
\hline Reference & & & Quartz & 90 & 89 \\
\hline \multirow[t]{2}{*}{2} & 1 & Vented & Quartz & 47 & 45 \\
\hline & 2 & Vented & Quartz & 40 & 25 \\
\hline 3 & 4 & Closed & Quartz & 88 & 80 \\
\hline Reference & & & $\mathrm{MgF}_{2}$ & 91 & n.d. \\
\hline \multirow[t]{2}{*}{2} & 3 & Vented & $\mathrm{MgF}_{2}$ & 32 & 30 \\
\hline & 4 & Closed & $\mathrm{MgF}_{2}$ & 90 & 88 \\
\hline \multirow[t]{2}{*}{3} & 2 & Vented & $\mathrm{MgF}_{2}$ & 6 & 4 \\
\hline & 3 & Closed & $\mathrm{MgF}_{2}$ & 88 & 88 \\
\hline
\end{tabular}

n.d. = no data.

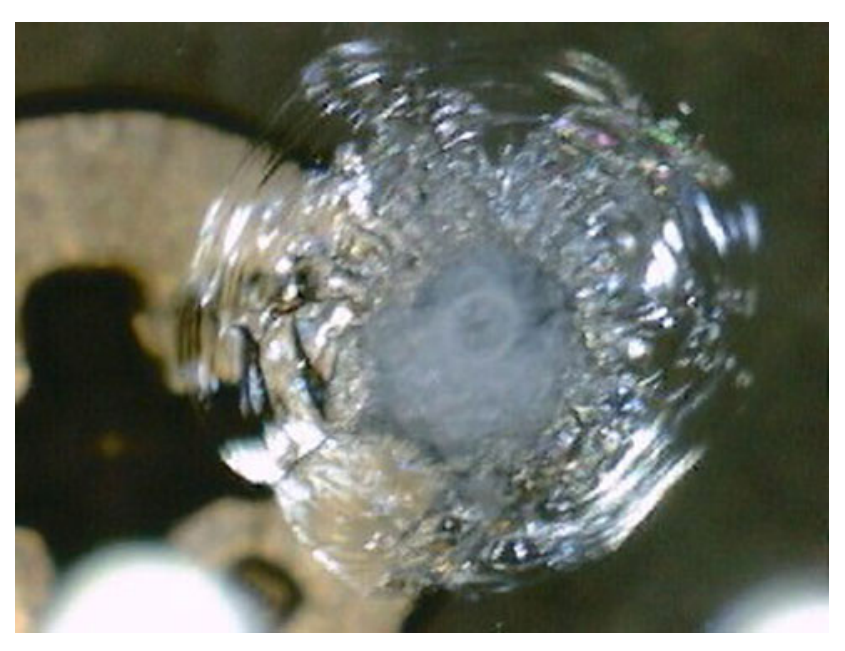

Fig. 6. Micrometeorite impact in the quartz top window of tray 2, compartment 2. Approximate diameter of the fracture: $4 \mathrm{~mm}$ (Credit RUAG).

themselves. Therefore, pressure around the ISS was considered similar as that for EXPOSE-E on EuTEF, where the Material Exposure and Degradation Experiment (MEDET) (Tighe et al. 2009) measured a pressure level of $\leq 10^{-7} \mathrm{~Pa}$ for the Wake direction, and $10^{-4} \mathrm{~Pa}$ for the Ram direction. EXPOSE-R was mostly pointing towards Wake. Therefore, a pressure range of $10^{-4}-10^{-7} \mathrm{~Pa}$ was estimated for that mission (Table 2).

Special events: ammonia venting

On May 15th, 2009 the ISS performed an ammonia venting activity announced well in advance. Valves of all three trays were commanded to close via TsUP on May 13th, 2009, at 13:28 UTC time in orbit 4050 . It took $4 \mathrm{~min}$ to close the three valves, capturing the space vacuum inside the trays to completely exclude the already unlikely risk of any ammonia gas from penetrating through the open valves of EXPOSE-R to the samples. All three valves were commanded to re-open well after end of the venting activity on May 28th, 2009, at UTC time 10:23 in 4 min.

\section{EXPOSE-R Mission Ground Reference}

\section{EXPOSE-R MGR overview}

In parallel to the space mission of EXPOSE-R, three flightidentical ground trays were used for the MGR performed at DLR Cologne, Germany, using the PSI (http://www.dlr.de/ spacesim). They were loaded with an identical set of biological and chemical samples and covered with optical filters as in the flight experiment; this was done simultaneously to the spaceflight preparation. The trays were filled with an Argon atmosphere and closed as for flight. They were stored at ambient temperature until the start of the MGR. Due to a belated availability of mission data, the MGR started with a delay of about 9 months on December 16th, 2009 with the evacuation of the vented compartments to reach a final pressure of $1.7 \times 10^{-3} \mathrm{~Pa}$. Then the temperature data obtained from EXPOSE-R on the ISS were analysed, each time point data averaged for the trays and fed into the MGR simulation programme of the PSI at the DLR. Simulated environmental exposure conditions were adjusted according to data of the flight experiment. For more than 22 months, pressure, temperature fluctuations and $\mathrm{UV}_{200-400 \mathrm{~nm}}$ radiation (solar simulator SOL 2000, Dr Hönle GmbH, Germany) similar to the space flight experiment were applied as far as technically possible. On ground irradiation fluences were applied according to the results of the RedShift Design and Engineering BVBA, Belgium (Beuselinck \& van Bavinchove 2011) modelling. On October 17th, 2011, the vented compartments were re-pressurized and samples were de-integrated under sterile conditions and returned to the investigators for analysis.

\section{EXPOSE-R MGR environment}

\section{EXPOSE-R MGR UV irradiation}

A Dr Hönle GmbH solar simulator SOL2000 without any optical filter emitting a continuous UV spectrum at wavelengths $\lambda>200 \mathrm{~nm}$ and shielded for personal protection with an aluminium tube was used. The resulting spectrum on top of the EXPOSE-R ground trays was measured with a calibrated Bentham 150 spectroradiometer (Gigahertz, Tuerkenfeld, Germany). Irradiance of the UV range 
$200-400 \mathrm{~nm}$ was $1.37 \mathrm{~kW} \mathrm{~m}-200-400 \mathrm{~nm}$. On ground UV (200$400 \mathrm{~nm}$ ) irradiation of the compartments was performed with fluences calculated from the RedShift derived total mission $\mathrm{SCh}$ for the individual compartments available at that time and the SORCE data (http:/lasp.colorado.edu/sorce/index.htm) (Table 5). Calculation of the irradiation fluences were restricted to the UV range of $200-400 \mathrm{~nm}$ because of the emission spectrum of the solar simulator $>200 \mathrm{~nm}$. Wavelengths longer than $400 \mathrm{~nm}$ are the major part of the solar and the solar simulator spectrum. Those values would mask the smaller but biologically more active values of the UV range.

\section{EXPOSE-R MGR atmosphere and pressure}

During the EXPOSE-R MGR, the compartments connected to the venting lines of the three ground trays were evacuated to a final pressure of $1.7 \times 10^{-3} \mathrm{~Pa}$ and the valves were closed. The pressure was kept during the whole MGR. Only the sample carriers of the experiments AMINO and ORGANIC with SEEDS turned out to be not tight enough to seal the tray when evacuated. Therefore, these carriers were accommodated in a temperature controlled vacuum facility of the PSI (http://www. dlr.de/spacesim) and also evacuated to $1.7 \times 10^{-3} \mathrm{~Pa}$. As in flight, the closed compartments not attached to the venting line remained filled with the ambient pressure argon gas.

\section{EXPOSE-R MGR temperature}

All available data on in flight temperatures were fed into the MGR and simulated on ground. The temperatures of the feedback control system measured at the tray structure (as in flight) during the MGR simulation ranged from $-24.7 \pm 2.0$ to $+49.5 \pm 2.0^{\circ} \mathrm{C}$, according to flight data. Because temperature data became available with a delay, calculated temperature data were not yet available and to shorten the MGR-duration to a flight similar time, the facility temperature was adjusted to each next temperature point as fast as possible. Time periods with missing data were ignored.

\section{Discussion}

With total mission duration of more than 2 years, an exposure duration to LEO environment of 682 days and a successful and safe return of the samples to the laboratories of the investigators, the EXPOSE-R mission was an overall successful astrobiological exposure mission. After the astrobiology experiment on the Long Duration Exposure Facility (LDEF) (Horneck et al. 1994), which lasted for nearly 6 years, EXPOSE-R was the second longest astrobiology mission in LEO. Although some data of environmental measurements were lost, the final total mission fluence for the individual samples was determined by calculations based on models. Most important, all samples were successfully transported to space, exposed to the specific space conditions in LEO as intended and returned to Earth safely for final on ground analysis.

The obtained results from EXPOSE-R, one of the longest international astrobiological exposure missions in LEO are collected in this issue (Berger et al. 2014; Bertrand et al. 2014;
Bérces et al. 2014; Bryce et al. 2014; Bryson et al. 2014; Carrasco et al. 2014; Cottin et al. 2014; Dachev et al. 2014; Mancinelli et al. 2014; Neuberger et al. 2014; Novikova et al. 2014; Panitz et al. 2014; Vergne et al. 2014).

There are several lessons learned that should be considered for improving and optimizing future exposure experiments in space:

\section{Pressure sensors}

The determination of the environmental LEO parameters is mandatory in particular for astrobiological exposure facilities and their experiments using the LEO environment as experimental setup. Pressure sensors should allow timeresolved measurements of the outside pressure and that inside the compartments at sample site. During the EXPOSE-E space flight, the neighbour experiment MEDET provided the only pressure data that were finally also used for assessing the values of the space vacuum for EXPOSE-R. There was no device to measure inner compartment pressure, neither for EXPOSE-E nor for EXPOSE-R.

\section{Redundant sensor and data management system}

On EXPOSE-R, a total of three systems were accommodated to measure extraterrestrial solar optical radiation: (i) the four UV sensors mounted at the four edges of the facility (Fig. 3), (ii) the radiometer mounted also on top of the facility (Fig. 3) and (iii) the active measurement device and experiment R3DR (Tables 1 and 2). All systems were activated via EXPOSE-R itself and data were linked to a single payload computer inside the ISS to be stored. The loss of data due to the failure of this computer, as experienced during the EXPOSE-R mission, would have been avoided by redundant HW availability. In any case, Earth orbiting facilities, even if being regularly visited as the ISS, are remote. Redundancy is an easy step to secure experiment success, even if it requires double amount of hardware and upload capacity.

Interpretation and analysis of passive exposure experiments depend on comprehensive data on the environment the experiment was exposed to. In addition to temperature measurements as close to the exposed sample as possible and irradiation measurements, preferable with a time resolution, monitoring of pressure and gaseous compounds of the environment would be of great interest. With EXPOSE-R, these data would have supported the analysis of the window contamination and possibly the determination of its source.

Because of the loss of measured UV data, the determination of the final mission fluences by calculations based on the ISS and EXPOSE-R geometry and the ISS attitude was required. This was possible due to the well-monitored flight behaviour of the ISS. Nevertheless, the determination of the window transmittance - averaged over the data taken before flight and then after flight, i.e. with contamination, remained a besteffort estimation based on the available pre- and post-mission data (Beuselinck \& van Bavinchove 2011). 


\section{Carrier selection}

The ISS provides several external platforms and structures for the accommodation of exposure experiments. Data download and commanding of a facility on the ISS is supported by a sophisticated network of space and ground based operations centres. In addition, astronaut support might be required, including special EVAs.

On the other side, such a huge and complex manned space station leads to constrains for the experiment:

The ISS facility itself may cast shadows of (optical) radiation in a difficult to predict way during a long-term mission, leading to heterogenous irradiation, as it was observed as gradient in the insolation over the whole exposure area of EXPOSE-R (Table 2). A multi-purpose facility as the ISS is restricted in its freedom of movement and travels on its predetermined route, attitude and height, thereby limiting a perpendicular orientation of a solar radiation exposure experiment facility as EXPOSE to the sun. As a result, insolation angles are varying and the dosimetry at sample site is difficult.

Safety is a major issue on spacecrafts involving humans, such as the ISS. This may complicate the selection of the test systems, which may pose possible hazards to the crew. Facilities like those of the EXPOSE family could also be implemented on unmanned free-flying satellites, thereby reducing the risk of safety problems to jeopardize the experiments. In addition, access to space on unmanned spacecrafts without respective safety considerations is usually easier and faster.

In particular, for experiments on manned spacecrafts, but also for all other space experiments, access to space simulation facilities in addition to the flight experiment is important to: (i) carefully prepare the space experiments; (ii) provide a mission parallel backup in case of major malfunctions or loss of experiments; (iii) provide valuable additional data for comparison and discrimination of effects induced by space parameters, especially if they show unexpected effects; and (iv) provide larger experimental space for additional experiments under space conditions, even if they are just performed under simulated space conditions.

Irrespective of constrains, difficulties and draw backs mentioned above, and the availability of sophisticated on ground space simulation facilities, access to space exposure missions is highly important because several environmental conditions in space, particularly the solar extraterrestrial UV spectrum and its combination with other space parameters, cannot be accurately simulated in ground-based laboratories. An exposure facility as EXPOSE-R, accommodated on a space vehicle such as ISS where the return of the samples is possible, provides an ideal environment for a controlled and long-term exposure of passive experiments, complementing the recent short-term astrobiological experiments on free-flying vehicles such as BIOPAN on BION and FOTON satellites (Horneck et al. 2001; Rettberg et al. 2004; Demets et al. 2005; Sancho et al. 2007; Jönsson et al. 2008; de la Torre et al. 2010; Raggio et al. 2011).

For the future, a new generation of scientific long-duration free-flying satellites returning by autonomous re-entry would significantly improve the accessibility of space for scientific experiments, making safety restrictions and long lead preparation times of experiments, as required for the ISS, unnecessary. The next generation of space exposure facilities, either on free-flying satellites or on the ISS should include realtime in-situ monitoring of biological and chemical phenomena and active measurements of their kinetics in response to exposure to selected space conditions, as already demonstrated by NASA's Organism/Organic Exposure to Orbital Stresses (O/OREOS) Nano-satellite Project (Woellert et al. 2011; Nicholson et al. 2011; Mattioda et al. 2012).

\section{Acknowledgements}

We dedicate this work to the memory of Hans Bruggmann from RUAG, who carefully performed the final integration of the flight experiment trays of EXPOSE-R. His dedicated work is sadly missed. The whole EXPOSE-R mission would not have been possible without the support of ESA, the Moscow control center TsUP and MUSC at the DLR, the payload developer Kayser-Threde and RUAG, and the Team leaders and the experimenter groups of EXPOSE-R. The authors wish to express their gratitude to all who made this mission a success.

\section{References}

Bérces, A., Egyeki, M., Fekete, A., Horneck, G., Kovács, G., Panitz, C. \& Ronto, Gy. (2014). The PUR experiment on the EXPOSE-R facility: Biological dosimetry of solar extraterrestrial UV radiation. Int. J. Astrobiol. (this issue)

Berger, T., Hajek, M., Bilski, P. \& Reitz, G. (2014). Cosmic radiation exposure of biological test systems during the EXPOSE-R mission. Int. J. Astrobiol. (this issue)

Bertrand, M., Chabin, A., Brack, A., Cottin, H., Chaput, D. \& Westall, F. (2012). The PROCESS experiment: exposition of amino acids in EXPOSE-E experiment on the International Space Station and in laboratories. Astrobiology 12(5), 426-435.

Bertrand, M., Chabin, A., Cadène, M., Chaput, D., Brack, A., Cottin, H., Laplace, S. \& Westall, F. (2014). The AMINO experiment: exposure of amino acids in the EXPOSE-R experiment on the International Space Science and in laboratory. Int. J. Astrobiol. (this issue).

Beuselinck, T. \& van Bavinchove, C. (2011). EXPOSE: environmental history by calculation EXPOSE-R simulation results. Report to ESA, EXP-RP-020-RS, Iss A, Rev.1.

Bryson, K.L., Salama, F., Elsaesser, A., Peeters, Z., Ricco, A.J., Foing, B.H. \& Goreva, Y. (2014). First results of the ORGANIC experiment on EXPOSE-R on the ISS. Int. J. Astrobiol. (this issue).

Bryce, C. C., Horneck, G., Rabbow, E., Edwards, H. G. M. \& Cockell, C. S. (2014). Impact shocked rocks as protective habitats on an anoxic early Earth. Int. J. Astrobiol. (this issue). doi: 10.1017/ S1473550414000123.

Bücker, H., Horneck, G., Wollenhaupt, H., Schwager, M. \& Taylor, G.R. (1974). Viability of Bacillus subtilis spores exposed to space environment in the M-191 experiment system aboard Apollo 16. Life Sci. Space Res. 12, 209-213.

Carrasco, N., Cottin, H., Cloix, M., Jérome, M., Bénilan, Y., Coll, P., Gazeau, M.-C., Raulin, F., Saiagh, K., Chaput, D., Szopa, C. (2014). The AMINO experiment: methane photolysis under solar VUV irradiation on the EXPOSE-R facility of the International Space Station. Int. J. Astrobiol. (this issue). doi: 10.1017/S1473550414000238. 
Cottin, H. (2011). Expose. In Encyclopedia of Astrobiology, ed. Gargaud, M., Amils, R., Quintanilla, J.C., Cleaves, H.J. III, Irvine, W.M., Pinti, D.L. \& Viso, M., vol. 1, pp. 558-560. Springer, Berlin-Heidelberg.

Cottin, H. et al. (2008). Heterogeneous solid/gas chemistry of organic compounds related to comets, meteorites, Titan, and Mars: laboratory and in lower Earth orbit experiments. Adv. Space Res. 42, 2019-2035.

Cottin, H. et al. (2012). The PROCESS experiment: an astrochemistry laboratory for solid and gas mixture in low Earth orbit. Astrobiology 12(5), $412-425$.

Cottin, H., Saiagh, K., Guan, Y.Y., Cloix, M., Khalaf, D., Macari, F., Jérome, M., Polienor, J.-M., Bénilan, Y., Coll, P., Fray, N., Gazeau, M.-C., Raulin, F., Stalport, F., Carrasco, N., Szopa, C., Bertrand, M., Chabin, A., Westall, F., Vergne, J., Da Silva, L.A., Maurel, M.-C., Chaput, D., Demets, R. \& Brack, A. (2014). The AMINO experiment: a laboratory for astrochemistry and astrobiology on the EXPOSE-R facility of the International Space Station. Int. J. Astrobiol. (this issue).

Dachev, T., Horneck, G., Häder, D.-P., Schuster, M. \& Lebert, M. (2014). EXPOSE-R cosmic radiation time profile. Int. J. Astrobiol. (this issue). doi: $10.1017 / \mathrm{S} 1473550414000093$.

de la Torre, R. et al. (2010). Survival of lichens and bacteria exposed to outer space conditions - results of the Lithopanspermia experiments. Icarus $\mathbf{2 0 8}$, 735-748.

Demets, R., Schulte, W. \& Baglioni, P. (2005). The past, present and future of Biopan. Adv. Space Res. 36, 311-316.

Demets, R., Bertrand, M., Bolkhovitinov, A., Bryson, K., Colas, C., Cottin, H., Dettmann, J., Ehrenfreund, P., Elsaesser, A., Jaramillo, E., Lebert, M., van Papendrecht, G., Pereira, C., Rohr, T., Saiagh, K. \& Schuster, M. (2014). Window contamination on Expose-R. Int. J. Astrobiol. (this issue).

Ehrenfreund, P. \& Foing, B.H. (1997). Fullerenes in space. Adv. Space Res. 19, 1033-1042.

Horneck, G. (1998). Exobiological experiments in Earth orbit. Adv. Space Res. 22(3), 317-326.

Horneck, G. (2011). Exposure Facilities. In Encyclopedia of Astrobiology, ed. Gargaud, M., Amils, R., Quintanilla, J.C., Cleaves, H.J. III, Irvine, W.M., Pinti, D.L. \& Viso, M., vol. 1, pp. 560-564. Springer, BerlinHeidelberg.

Horneck, G. \& Brack, A. (1992). Study of the origin, evolution and distribution of life with emphasis on exobiology experiments in Earth orbit. In Advances in Space Biology and Medicine, ed. Bonting, S.L., vol. 2, pp. 229-262. JAI Press, Greenwich, CT.

Horneck, G., Bücker, H., Reitz, G., Requardt, H., Dose, K., Martens, K.D., Mennigmann, H.D. \& Weber, P. (1984). Microorganisms in the space environment. Science 225, 226-228.

Horneck, G., Cadet, J., Dose, K., Fritz-Niggli, H. \& Kiefer, J. (1988). ERA follow-on scientific study: perspectives of exobiological and radiation biological research by use of free-flying carriers in Earth orbit. Final Report. ESA Contract No. 8116/88/F7BZ/(SC) European Space Agency, Paris, France.

Horneck, G., Bücker, H. \& Reitz, G. (1994). Long-term survival of bacterial spores in space. Adv. Space Res. 14(10), 41-45.

Horneck, G., Rettberg, P., Reitz, G., Wehner, J., Eschweiler, U., Strauch, K., Panitz, C., Starke, V. \& Baumstark-Khan, C. (2001). Protection of bacterial spores in space, a contribution to the discussion on Panspermia. Orig. Life Evol. Biosph. 31, 527-547.

Horneck, G., Klaus, D.M. \& Mancinelli, R.L. (2010). Space microbiology. Microbiol. Mol. Biol. Rev. 74, 121-156.

Horneck, G. et al. (2012). Resistance of bacterial endospores to outer space for planetary protection purposes-experiment PROTECT of the EXPOSE-E mission. Astrobiology 12(5), 445-456.

Jönsson, K.I., Rabbow, E., Schill, R.O., Harms-Ringdahl, M. \& Rettberg, P. (2008). Tardigrades survive exposure to space in low Earth orbit. Curr. Biol. 18, R729-R731.

Kuzicheva, E.A. \& Gontareva, N.B. (2001). Study of the peptide prebiotic synthesis in context of exobiological investigations on earth orbit. $A d v$. Space Res. 28(4), 713-718.
Kuzicheva, E.A. \& Gontareva, N.B. (2002). Prebiotic synthesis of nucleotides at the Earth orbit in presence of Lunar soil. Adv. Space Res. 30(6), 1525-1531.

Mancinelli, R.M. et al. (2014). The affect of the space environment on the survival of Halorubrum chaoviatoris and Synechococcus (Nägeli): Data from the Space Experiment OSMO on EXPOSE-R. Int. J. Astrobiol. (this issue).

Mattioda, A. et al. (2012). The O/OREOS Mission: first science data from the Space Environment Viability of Organics (SEVO) payload. Astrobiology 12(9), 841-853.

Moeller, R., Reitz, G., Nicholson, W.L., the PROTECT Team \& Horneck, G. (2012). Mutagenesis in bacterial spores exposed to space and simulated martian conditions: data from the EXPOSE-E spaceflight experiment PROTECT. Astrobiology 12(5), 457-468.

Neuberger, K., Lux-Enddrich, A., Panitz, C. \& Horneck, G. (2014). Survival of spores of Trichoderma longibrachiatum in space: Data from the space experiment SPORES on EXPOSE-R. Int. J. Astrobiol. (this issue).

Nicholson, W.L. et al. (2011). The O/OREOS mission: first science data from the Space Environment Survivability of Living Organisms (SESLO) payload. Astrobiology 11, 951-958.

Nicholson, W.L., Horneck, G., Moeller, R. \& the PROTECT Team (2012). Global transcription responses during germination of Bacillus subtilis spores after 18 months in space on the EXPOSE-E Experiment PROTECT. Astrobiology 12(5), 469-487.

Noblet, A. et al. (2012). The PROCESS experiment: evolution of amino acids and carboxylic acids submitted to Mars surface UV radiation conditions in low earth orbit. Astrobiology 12(5), 436-444.

Novikova, N., Deshevaya, E., Levinskikh, M., Polikarpov, N., Poddubko, S. $\&$ Sychev, V. (2014). Study of the effects of the space environment on dormant forms of biological specimens. Int. J. Astrobiol. (this issue).

Onofri, S., de la Torre, R., de Vera, J.-P., Ott, S., Zucconi, L., Selbmann, L., Scalzi, G., Venkateswaran, K.J., Rabbow, E. \& Horneck, G. (2012). Hitchhikers between planets?-Rock-colonising organisms survive 1.5 years in outer space. Astrobiology 12(5), 508-516.

Panitz, C., Horneck, G., Rabbow, E., Rettberg, P., Moeller, R., Cadet, J., Douki, T. \& Reitz, G. (2014). The SPORES experiment of the EXPOSE-R mission: Bacillus subtilis spores in artificial meteorites. Int. J. Astrobiol. (this issue). doi: 10.1017/S1473550414000251.

Pereira, C. \& Jaramillo, E. (2011). EXPOSE-R Post-flight Inspection of Windows. RUAG, Doc. Nr. EXR-TR-HT-010, issue 2.

Rabbow, E. et al. (2009). EXPOSE, an astrobiological exposure facility on the International Space Station - from Proposal to Flight, Orig. Life Evol. Biosph. 39, 581-598.

Rabbow, E., et al. (2012). EXPOSE-E: an ESA Astrobiology Mission 1.5 Years in Space. Astrobiology 12(5), 374-386, doi: 10.1089/ ast.2011.0760.

Raggio, J., Pintado, A., Ascaso, C., De La Torre, R., De Los Ríos, A., Wierzchos, J., Horneck, G. \& Sancho, L.G. (2011). Whole lichen thalli survive exposure to space conditions: results of Lithopanspermia experiment with Aspicilia fruticulosa. Astrobiology 11, 281-292.

Rettberg, P., Rabbow, E., Panitz, C. \& Horneck, G. (2004). Biological space experiments for the simulation of Martian conditions: UV radiation and Martian soil analogues. Adv. Space Res. 33, 1294-1301.

Sancho, L.G., de la Torre, R., Horneck, G., Ascaso, C., de los Rios, A., Pintado, A., Wierzchos, J. \& Schuster, M. (2007). Lichens survive in space: results from the 2005 LICHENS experiment. Astrobiology 7, 443-454.

Tepfer, D., Zalar, A. \& Leach, S. (2012). Survival of plant seeds for 18 months outside the International Space Station. Astrobiology 12(5), $517-528$.

Tighe, A.P., Iwanovsky, B., van Eesbeek, M. \& Duzellier, S. (2009). In-orbit measurements of the Columbus Lab vacuum environment using the MEDET pressure gauge. Presented at the Int. Symp. on Materials in the Space Environment ISMSE-11, Aix-en-Provence, France, September 2009.

Vaishampayan, P.A., Rabbow, E., Horneck, G. \& Venkateswaran, K. (2012). Survival of Bacillus pumilus spores for prolonged period of time in real space conditions. Astrobiology 12(5), 487-497. 
Vergne, J., Cottin, H., da Silva, L., Brack, A., Chaput, D. \& Maurel, M.-C. (2014). The AMINO experiment: RNA stability under solar radiation studied on the EXPOSE-R facility of the International Space Station. Int. J. Astrobiol. (this issue). doi: 10.1017/S147355041400024X.

Wassmann, M., Panitz, C., Rabblow, E., Moeller, R., Reitz, G., Douki, T., Cadet, J. \& Rettberg, P. (2012). Exposure of UV-evolved spores of Bacillus subtilis to low Earth orbit and simulated Mars conditions - data of the experiment ADAPT, preflight and Mission Ground Reference. Astrobiology 12(5), 498-507.
Woellert, K., Ehrenfreund, P., Ricco, A.J. \& Hertzfeld, H. (2011). Cubesats: cost-effective science and technology platforms for emerging and developing nations. Adv. Space Res. 47, 663-684.

http://ooreos.engr.scu.edu/dashboard.htm http://wwwsolar.nrl.navy.mil/solar_spectra.html. http://www.go.dlr.de/musc/expose/telemetrie.php) http://www.dlr.de/spacesim http://lasp.colorado.edu/sorce/index.htm 